\title{
Determinants and Influential Factors in Technology Valuation in Korea
}

\author{
Hyun-Woo Park \\ Korea Institute of Science and Technology Information \\ Seoul, 130-741, Korea \\ Woo-Taek Shin \\ Shattuck St. Mary's School \\ Faribault, MN 55021, USA
}

\begin{abstract}
This study empirically analyzes the characteristics of the various attributes of technology that influence the economic values of technologies, based on the cases of technology valuation carried out in Korea. To do so, we collect the cases of technology valuation carried out by major technology valuation institutions in Korea and extract from these data the information about various characteristics of the subject technologies of valuation and the primary factors applied to the technology valuation. Based on such extracted information, we examine the overall trends of technology valuation in Korea and analyze how the main factors of technology valuation vary with the attributes of technology.
\end{abstract}

Keywords: technology valuation, discounted cash flow, determinants of technology value, intrinsic attributes, application attributes

\section{INTRODUCTION}

This research investigates the actual cases of technology valuation in Korea to analyze the characteristics and influences of the primary factors that influence the determination of technology values. To do so, we first collect the data of technology valuation carried out by major institutions of technology valuation and observe the general trends and characteristics of determinants of technology valuation. Then, we analyze how technology value, life span of technology, discount rate, and level of contribution of technology vary with the intellectual property right type, stage of commercialization, evaluation purpose, technology field, and industry field, and how these determinants of technology valuation influence the final technology value.

In this paper, the analysis is carried out based on the publicized cases of technology valuation conducted by professional institutions and the actual cases from which information needed for analysis could be extracted. Much of the contents of technology valuation are not fundamentally open to public since the technologies developed or owned by private corporations are related with the business secrets. Therefore, it is a reality that the quantitatively limited cases of the analysis serve as the obstacles to reliable results and empirical analysis for extracting objective implications.

\footnotetext{
*Corresponding author.E-mail : hpark@kisti.re.kr Manuscript received Jun.15, 2010 ; accepted Jul. 20, 2010
}

\section{ANALYTICAL FRAMEWORK OF INFLUENTIAL FACTORS IN TECHNOLOGY VALUATION}

\subsection{Determination of Technology Values}

Models or techniques for valuation are diverse just as usages of technology valuation are diverse, and it is a reality that even the same model shows diverse features according to analyzers in applying variables that significantly impact on values of technology.

In particular, in applying DCF (discounted cash flow) based Income Approach, economic life span of technology must be estimated for calculation of the future income flow produced by commercialization of the subjects of technology valuation, and level of contribution of technology must be judged in order to separate the part that the technology has contributed from the flow of total income. In addition, a proper discount rate must be determined in order to convert future cash flow into present values. Besides, establishing various assumptions and determining variables are required in valuation methods of general income approach.

First of all, various methods can be applied for determining economic life span of technology. In case when the subject of technology valuation is patent technology, the legal life span of patent can be simply considered or the analyses of applicants or citations using information of patent applications of relevant fields in the past can be utilized. In addition, period of life span of products with application of relevant technologies can be 
referenced. As methodologies for analyses of life span of utilized or methodologies such as analyses of rankings and trends using database, citation analysis, co-word, and cocitation can be also utilized.

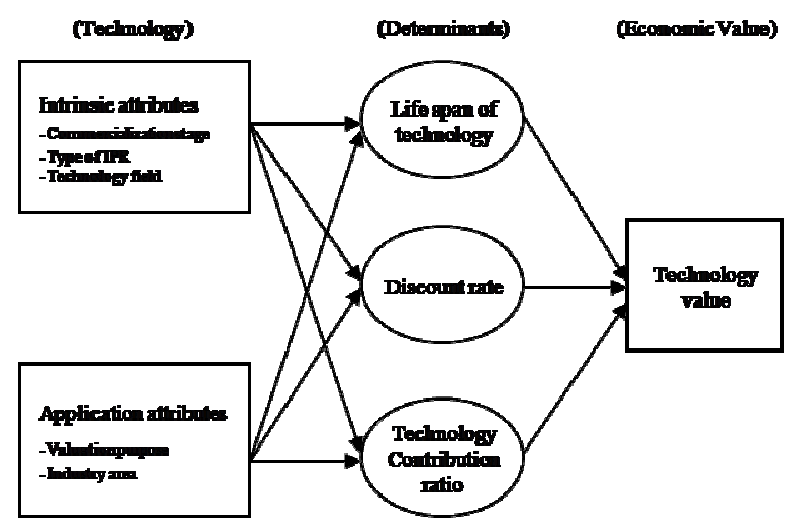

Fig. 1. Determination of Technology Value

In determining the level of contribution of technology, various methods are utilized. The most common method of determining the contribution level of technologies is technology factor method; technology factor means the scope that technology itself takes among estimated portions of increase of cash flow generated by uses of specific technologies within specific corporations. This technology factor method is said to have been suggested by Arthur D. Little [6]. According to this, the scope of changes of technology factor is determined by the number evaluated in quantity of the contribution to corporations made by superior competitiveness of technology. Before this, Dow Chemical had measured technology factor using utility attributes and competitiveness attributes after evaluating present values of additional cash flow. The US National Technology Transfer Center is carrying out evaluation regarding possibility of commercial survival of technologies by expanding indices for evaluating utility attributes and competitiveness attributes with technology factor method of Dow Chemical as a basic model. Inavisis, San Diego based IP management company, is calculating techno-logy factors in consideration of industrial factors and individual technology ratings. On the other hand, UNIDO explains about technology pricing in technology transfer through the concept of LSLP (licensor's share of licensee's profit) [10], which can be also said to share the same meaning with the concept of the level of contribution of technology. Besides, rules of thumb, in which a certain part $(25 \%$ or $33 \%)$ of income flow produced by commercialization of technologies is considered the contribution of technologies, are also used [7].

Consequent risks of commercialization of technologies are classified largely into systematic risks and non-systematic risks. Systematic risks are caused by common factors of the entire capital market and are difficult to remove or to avoid. Nonsystematic risks are caused by unique factors of corporations and are possible to remove. As the methods of determining discount rate for converting the future cash flow into present value by reflecting these risks, WACC (weighted average cost of capital), Risk Premium or Built-up Method are utilized, and required rate of return applied by venture capitalists in the technologies, information analyses such as bibliometrics can be United States when estimating new venture investments is also utilized.

Because the establishment of various assumptions and the estimation of various variables besides the above important variables are accompanied and change final amounts of valuation, it can be said that feasibility and credibility of valuations are determined by on how much reliable and objective ground estimations or calculations of these variable are carried out.

\subsection{Method of Analysis}

In order to analyze the influential factors of determination of technology values, with the estimated amount of technology value as a dependent variable and valuation purpose, stage of commercialization, type of intellectual property right, technology field, and industry area as explanatory variables, categorical regression analysis is carried out. Categorical regression is a method of converting categorical variables into optimum scale for finding out which variable provides important impacts on dependent variables and observing which variable among each several categorical variables is important.

Ordinary regression analysis is the statistical technique that aims at explaining or predicting the relation between a dependent variable and independent variables. Here, in case when independent variables are continuous, linear regression is utilized if a dependent variable is also continuous while logistic regression is utilized if a dependent variable is binary.

However, if independent variables are categorical data, it may be difficult to apply the ordinary regression model. This is because the data violate the assumptions of normality or homoscedasticity on error terms. In these cases, the general linear model can be utilized, but categorical regression analysis can be used to gain more useful results. Ordinary regression analysis estimates regression coefficients by least squares. On the other hand, categorical regression analysis acquires optimized linear regression equation using variables transformed through optimal scaling using alternating least squares. The analysis produces an optimal level for nominal, ordinal or continuous variables, and do not need to have the assumptions on the distribution of variables. In categorical regression, optimal scaling means a method of data analysis in which the measurement characteristics of data are reflected but observed categories are granted numerical values so that the relation between observations and data analysis model can be optimized. Alternating least squares means an algorithm which carries out repeatedly the stage of model estimation by least squares and the stage of optimal scaling of data in turn.

\section{CHARACTERISTICS OF TECHNOLOGY VALUATION IN KOREA}

\subsection{Characteristics of Collected Data}

This study performed the analysis based on the data of the latter half of 2000s, when technology valuation, along with technology transfer and commercialization, and technology investment, got into its stride. The contents of technology valuation are rarely publicized because they include the internal 
information of corporations. It was therefore very difficult to obtain the data for analysis.

Specifically, the valuation reports of the organizations that have professionally conducted technology valuation, such as Korea Technology Transfer Center, Korea Technology Finance Corporation, Korea Invention Promotion Association, Korea Institute of Science and Technology Information, and Korea Development Bank, were used for research. Additionally, valuation data that were open to public and could provide information needed for analysis were collected from Korea Valuation Association, some universities and patent offices.

Among the entire valuation data collected for analysis, 956 cases include substantial information needed for the analysis of the main variables that reflect technology value. The estimated amount of technology value varied from 0 to 61,622 million won, and the average was $1,175.8$ million won.

\subsection{General Characteristics of Technology Valuation in Korea}

We can examine the general characteristics of technology valuation in Korea in terms of the attributes of subject technologies, such as purpose of valuation, stage of commercialization, type of intellectual property right (IPR), technology field, and industry area.

To begin with, when the cases of technology valuation are classified by valuation purposes, among the entire 956 cases of valuation, there are 165 cases for technology transfer and transaction, 149 cases for technology investment, 67 cases for investment promotion, 466 cases for loan on security, accounting for $48.7 \%$, the highest percentage, and 106 other cases, as in Tab. 1. The economic value of technologies was the highest in investment promotion with the average of 3,360.5 million won and in technology transfer with the average of 2,189.7 million won. On the other hand, lawsuit brings about the lowest with the average of 177.3 million won and technology investment and loan on security have the relatively low averages.

Table 1. Technology Valuation by Purpose of Valuation

\begin{tabular}{c|rc|r|r|r}
\hline \multirow{2}{*}{ Valuation Purpose } & \multicolumn{2}{|c|}{$\begin{array}{c}\text { Number of } \\
\text { Cases (\%) }\end{array}$} & \multicolumn{3}{|c|}{ Technology Value (million won) } \\
\cline { 3 - 6 } & \multicolumn{2}{|c}{ Minimum } & Maximum & Average \\
\hline Technology Transfer & 165 & $(17.3)$ & 0.0 & $61,622.0$ & $2,189.7$ \\
\hline Technology investment & 149 & $(15.6)$ & 10.0 & $21,659.0$ & 856.8 \\
\hline Investment promotion & 67 & $(7.0)$ & 167.0 & $15,241.0$ & $3,360.5$ \\
\hline Loan on security & 466 & $(48.7)$ & 50.0 & $6,683.0$ & 749.9 \\
\hline Lawsuit & 3 & $(0.3)$ & 61.0 & 398.0 & 177.3 \\
\hline Others & 106 & $(11.1)$ & 13.0 & $3,756.0$ & 565.8 \\
\hline
\end{tabular}

Note: Million Korean won $=$ US\$850

Next, when the cases are classified by stages of commercialization, there are 6 cases at the idea stage of technology, 75 cases at the research and development, 109 cases at the completion of $R \& D, 217$ cases at the completion of prototype, 132 cases at the completion of product, and 417 cases at the production and sale, which accounts for the largest percentage of $43.6 \%$, shown in Tab. 2. At the stage of completion of product and research \& development, technologies were valued the highest with averages of $1,720.5$ and 1,429.0 million won. On the other hand, the stages of idea generation and completion of $\mathrm{R} \& \mathrm{D}$ show the lowest averages.
Table 2. Technology Valuation by Stage of Commercialization

\begin{tabular}{c|rc|r|r|r}
\hline \multirow{2}{*}{ Commercialization Stage } & \multirow{2}{*}{$\begin{array}{c}\text { Number of Cases } \\
(\%)\end{array}$} & \multicolumn{2}{|c}{ Technology Value (million won) } \\
\cline { 4 - 7 } & & Minimum & Maximum & Average \\
\hline Idea generation & 6 & $(0.6)$ & 61.0 & 832.0 & 414.0 \\
\hline Research \& development & 75 & $(7.8)$ & 0.0 & $21,659.0$ & $1,429.0$ \\
\hline Completion of R\&D & 109 & $(11.4)$ & 8.0 & $33,956.0$ & 875.9 \\
\hline Completion of prototype & 217 & $(22.7)$ & 1.0 & $61,622.0$ & $1,151.0$ \\
\hline Completion of product & 132 & $(13.8)$ & 3.6 & $20,450.0$ & $1,720.2$ \\
\hline Production \& Sale & 417 & $(43.6)$ & 8.0 & $16,510.0$ & $1,060.2$ \\
\hline
\end{tabular}

Third, when the cases are classified by the types of intellectual property rights, there are 799 cases of patent registration, accounting for a majority of $83.6 \%, 74$ cases of patent application, 33 cases of utility model registration, and 38 cases of no IPR, summarized in Tab. 3. Technologies that do not have IPR were valued the highest and software technologies were valued the lowest.

Table 3. Technology Valuation by Type of IPR

\begin{tabular}{c|rc|r|r|r}
\hline \multirow{2}{*}{ IPR Type } & \multicolumn{2}{|c|}{$\begin{array}{c}\text { Number of Cases } \\
(\%)\end{array}$} & \multicolumn{2}{|c}{ Technology Value (million won) } \\
\cline { 4 - 7 } & \multicolumn{2}{|c|}{ Minimum } & Maximum & Average \\
\hline Patent registration & 799 & $(83.6)$ & 0.0 & $61,622.0$ & $1,139.8$ \\
\hline Patent application & 74 & $(7.7)$ & 8.0 & $33,956.0$ & $1,406.2$ \\
\hline Utility Model registration & 33 & $(3.5)$ & 1.0 & $11,273.0$ & $1,227.7$ \\
\hline Utility Model application & 5 & $(0.5)$ & 253.0 & $1,000.0$ & 665.6 \\
\hline Software registration & 5 & $(0.5)$ & 20.0 & 634.0 & 338.4 \\
\hline Other type of IPR & 2 & $(0.2)$ & 690.0 & 752.0 & 721.0 \\
\hline No IPR & 38 & $(4.0)$ & 55.0 & $12,009.0$ & $1,640.8$ \\
\hline
\end{tabular}

Fourth, Tab. 4 shows the cases classified by technology field. As seen in the table, machinery accounts for 233 cases with the highest percentage of $24.4 \%$, the largest number of cases, information \& communication 161 cases, electricity \& electronics 138 cases and materials 104 cases, shown in Table 5 . Natural science including physical science, chemistry, and earth science has only 13 cases and energy \& resources has 24 cases. Economic value of technologies was the highest in the fields of life science, and relatively high in the fields of energy \& resources and environment, while low in the fields of natural science, chemical engineering, construction \& transportation, information \& communication, etc.

Table 4. Technology Valuation by Technology Field

\begin{tabular}{c|rc|r|r|r}
\hline \multirow{2}{*}{ Technology Field } & \multicolumn{2}{|c|}{$\begin{array}{c}\text { Number of Cases } \\
(\%)\end{array}$} & \multicolumn{3}{|c}{ Technology Value (million won) } \\
\cline { 4 - 7 } & & Minimum & Maximum & Average \\
\hline Natural science & 13 & $(10.3)$ & 71.0 & $1,633.0$ & 628.7 \\
\hline Life science & 46 & $(4.8)$ & 11.0 & $61,622.9$ & $2,310.8$ \\
\hline Health and medicine & 58 & $(6.1)$ & 10.0 & $6,120.0$ & $1,140.3$ \\
\hline Machinery & 233 & $(24.4)$ & 8.0 & $18,227.0$ & 972.7 \\
\hline Materials & 104 & $(10.9)$ & 0.0 & $21,659.0$ & $1,457.0$ \\
\hline Chemical engineering & 50 & $(5.2)$ & 78.0 & $7,455.0$ & 847.3 \\
\hline Electricity \& electronics & 138 & $(14.4)$ & 3.6 & $33,956.0$ & $1,399.6$ \\
\hline Information\&communication & 161 & $(16.8)$ & 13.0 & $12,009.0$ & 924.8 \\
\hline Energy \& resources & 24 & $(2.5)$ & 83.0 & $16,510.0$ & $1,740.2$ \\
\hline Environment & 37 & $(3.9)$ & 150.0 & $11,709.0$ & $1,639.5$ \\
\hline Const. \& transportation & 92 & $(9.6)$ & 34.0 & $7,332.0$ & 853.1 \\
\hline
\end{tabular}

Fifth, Tab. 5 displays the cases classified by industry area. In particular, industrial machinery area accounts for 283 cases, the 
largest number of cases, electricity \& electronics 174 cases, and service industry 142 cases, shown in Table 6. Transportation equipment, furniture \& other products, and food, clothing and lumber areas have the relatively small number of cases. The economic value of technologies was evaluated the highest in the areas of petroleum \& chemistry, nonmetallic mineral product and transportation equipment, and the lowest in the areas of food, clothing \& lumber, furniture \& other products, and service industry.

Table 5. Technology Valuation by Industry Area

\begin{tabular}{c|rc|r|r|r}
\hline \multirow{2}{*}{ Industry Area } & \multicolumn{2}{|c|}{$\begin{array}{c}\text { Number of Cases } \\
(\%)\end{array}$} & \multicolumn{3}{|c}{ Technology Value (million won) } \\
\cline { 4 - 7 } & \multicolumn{2}{|c|}{ Minimum } & Maximum & Average \\
\hline Food, clothing \& lumber & 40 & $(4.2)$ & 19.0 & $2,262.0$ & \multicolumn{1}{c}{676.0} \\
\hline Petroleum \& chemistry & 96 & $(10.0)$ & 10.0 & $61,622.0$ & $1,792.8$ \\
\hline Nonmetallic mineral product & 61 & $(6.4)$ & 40.0 & $20,450.0$ & $1,731.0$ \\
\hline Metal product & 62 & $(6.5)$ & 0.0 & $11,681.0$ & $1,143.6$ \\
\hline Industrial machinery & 263 & $(27.5)$ & 1.0 & $18,227.0$ & 946.6 \\
\hline Electricity \& electronics & 174 & $(18.2)$ & 12.0 & $33,956.0$ & $1,443.4$ \\
\hline Transportation equipment & 27 & $(2.8)$ & 134.0 & $11,273.0$ & $1,658.9$ \\
\hline Furniture \& other products & 21 & $(2.2)$ & 30.0 & $2,798.0$ & 759.4 \\
\hline Construction & 52 & $(5.4)$ & 101.0 & $10,034.0$ & $1,044.0$ \\
\hline Service industry & 142 & $(14.9)$ & 20.0 & $5,071.0$ & 698.4 \\
\hline Other industries & 18 & $(1.9)$ & 24.0 & $11,709.0$ & $1,896.3$ \\
\hline
\end{tabular}

\section{INFLUENTIAL FACTORS IN DETERMINING TECHNOLOGY VALUES}

\subsection{Importance of Technology Attributes}

We executed a categorical regression analysis with a dependent variable, the economic values of technologies as a continuous variable and independent variables including purpose of valuation, stage of commercialization, type of intellectual property, technology field, and industry area as categorical variables. The results of analysis are as follows.

The table of coefficients in Tab. 6 shows the categorical regression model estimated through betas of coefficients as follows. In the model, each variable indicates a standardized one. According to beta coefficients in the table, valuation purpose is the most influential variable and the IPR type is the least influential variable on the economic value of a certain technology in technology valuation.

Table 6. Coefficients

\begin{tabular}{|c|c|c|c|c|c|}
\hline & \multicolumn{2}{|c|}{ Standardized Coefficients } & \multirow[b]{2}{*}{ d.f. } & \multirow[b]{2}{*}{$\mathrm{F}$} & \multirow[b]{2}{*}{ Sig. } \\
\hline & B & Std. Error & & & \\
\hline Valuation Purpose & -.370 & .030 & 5 & 151.481 & .000 \\
\hline Stage of Commercialization & .139 & .031 & 5 & 20.486 & .000 \\
\hline Type of IPR & .097 & .031 & 6 & 10.035 & .000 \\
\hline Technology Field & .121 & .031 & 10 & 15.358 & .000 \\
\hline Industry Area & -.157 & .031 & 10 & 25.808 & .000 \\
\hline
\end{tabular}

Table 7. Correlation Coefficients

\begin{tabular}{c|c|c|c|c}
\hline \multirow{2}{*}{} & \multicolumn{3}{|c|}{ correlation coefficient } & \multirow{2}{*}{ Importance } \\
\cline { 2 - 5 } & tolerance & Partial & part & \\
\hline Valuation Purpose & -.372 & -.376 & -.366 & .730 \\
\hline Stage of Commercialization & .154 & .148 & .134 & .113 \\
\hline Type of IPR & .030 & .104 & .094 & .016 \\
\hline Technology Field & .078 & .128 & .116 & .050 \\
\hline
\end{tabular}

\begin{tabular}{|l|l|l|l|l|}
\hline Industry Area & -.109 & -.165 & -.151 & .091 \\
\hline
\end{tabular}

Correlation coefficients are shown in Tab. 7, in which the values of importance tell how each variable has an influence on technology values. In this table, the importance of valuation purpose is the greatest with the value of 0.730 as seen in beta coefficients. The values of importance are proportioned to the absolute value of standardized regression coefficients. Next to valuation purpose, technology field, the stage of commercialization, and industry area are relatively more important while IPR type and technology field are the least important in technology valuation.

From the above, we can see that the application attributes of a subject technology such as valuation purpose and industry area are more important than the intrinsic attributes of the technology in technology valuation. This could mean that the economic value of a certain technology depends largely on how the technology is utilized.

\subsection{Influence of Technology Attributes}

Tab. 8 summarizes the optimally scaled values of categorical variables. In valuation purpose, investment promotion is the category that is expected to have the highest values for technology, considering that the sign of the standardized regression coefficient of valuation purpose is negative in Table 7. In the stage of commercialization, completion of product is the category that is expected to have the highest values of technologies while idea generation is expected to have the lowest values of technologies. In the type of IPR, no IPR is the category that is expected to have high values of technologies while utility model registration is expected to have lower values of technologies.

Table 8. Quantification of Variables

\begin{tabular}{c|l|r|r}
\hline \multicolumn{1}{c|}{ category } & frequency & quantification \\
\hline \multirow{5}{*}{ Valuation } & Technology transfer & 165 & -.655 \\
Purpose & Technology investment & 149 & .973 \\
& Investment promotion & 67 & -3.172 \\
& Loan on security & 466 & .232 \\
& Lawsuit & 3 & 1.692 \\
& Others & 106 & .586 \\
\hline \multirow{5}{*}{ Stage of } & Idea generation & 6 & -5.097 \\
Commerciali & Research \& development & 75 & -.443 \\
zation & Completion of R\&D & 109 & -1.865 \\
& Completion of prototype & 217 & -.584 \\
& Completion of product & 132 & 1.253 \\
& Production \& sale & 417 & .548 \\
\hline \multirow{5}{*}{ Type of IPR } & Patent registration & 799 & .077 \\
& Patent application & 74 & .476 \\
& Utility Model registration & 33 & -4.883 \\
& Utility Model application & 5 & 4.479 \\
& Software registration & 5 & -.019 \\
& Other type of IPR & 2 & -.198 \\
& No IPR & 38 & 1.116 \\
\hline
\end{tabular}




\begin{tabular}{c|l|r|r}
\hline & Natural science & 13 & -2.565 \\
& Life science & 46 & -1.165 \\
& Health \& medicine & 58 & .494 \\
Technology & Machinery & 233 & -.250 \\
Field & Materials & 104 & -1.008 \\
& Chemical engineering & 50 & -2.032 \\
& Electricity \& electronics & 138 & .031 \\
& Information \& communication & 161 & .786 \\
& Energy \& resources & 37 & 2.599 \\
& Environment & 92 & 2.208 \\
& Construction \& transportation & 24 & .522 \\
\hline \multirow{5}{*}{ Industry Area } & Food, clothing \& lumber & 40 & .745 \\
& Petroleum \& chemistry & 96 & -1.549 \\
& Nonmetallic mineral product & 61 & -.870 \\
& Metal product & 62 & -.348 \\
& Electricity \& electronics & 263 & .368 \\
& Transportation equipment & 174 & -.468 \\
& Furniture \& other products & 27 & -1.906 \\
& Construction & 21 & .449 \\
& Service industry & 52 & 1.226 \\
& Other industries & 142 & 1.416 \\
& 18 & -2.483 \\
\hline
\end{tabular}

In technology field, technologies in the fields of energy \& resources and environment are the categories that are expected to have higher values while technologies in the fields of natural science and chemical engineering are expected to have low values. In industry area, technologies in the areas of petroleum $\&$ chemistry and transportation equipment are the categories that are expected to have the highest values while technologies in the areas of service industry and construction are expected to have the lowest values, considering the negative sign of the standardized regression coefficient of industry area in Tab. 6.

\section{CONCLUSION}

We, using the cases of technology valuation in Korea, reviewed how technology value and the determinants of valuation by DCF-based income approach including life span of technology, discount rate, and technology contribution ratio are determined, and analyzed how differences are made in the 3 determinant factors according to the purpose of valuation, stage of commercialization, type of IPR, techno-logy field, and industry area of subject technologies. In addition, we attempted to analyze how each factor affects the determination of technology value.

Based on the collected data, we analyzed the characteristics of technology valuation in Korea in various aspects. First of all, we found out that the economic values of technologies showed differences on average according to purposes of valuation, technology field and industry area. Next, we identified differences in determinants applied to valuation approach, and therefore differences of estimated technology values, depending upon technological attributes of each subject technology.

In addition, we carried out the influential factors in determining technology value, and made certain that the attributes of technology have different impacts on final value of technology. More interestingly, the application attributes of technologies such as valuation purpose and industry area have more importance and influence that the intrinsic attribute in technology valuation in Korea.

We need to point out that the analyses in this paper were based on the limited information on technology valuation, and therefore, be cautious when interpreting the results of the analyses. We will be able to perform more reasonable, empirical and theoretical verification of determinants of technology valuation if we collect much broader cases of technology valuation and secure additional information on valuation factors in the future. We believe that systematic accumulation of information and continuous research can help establish methodology for more objective technology valuation, and implement more efficient technology transfer and commercialization.

\section{REFERENCES}

[1] Guellec, Dominique and van Pottelsberghe de la Potterie, Bruno, "Application, Grants and the Value of Patent," Economics Letters 69, 2000, pp.109-114.

[2] Hirschey, M. and Richardson, V. J., "Valuation Effects of Patent Quality: A Comparison for Japanese and U.S. Firms," Pacific-Basin Finance Journal 9, 2001, pp.65-82.

[3] Hunt, F. H., Probert, D. R., Wong, J. C., and Phaal, R., "Valuation of technology: exploring a practical hybrid model," PICMET 2003, Portland USA, 20-24 July 2003.

[4] Kossovsky, N., "Fair Value of Intellectual Property: An Option-based Valuation of Nearly 8,000 Intellectual Property Assets," Journal of Intellectual Capital, 3(1), 2002, pp.62-70.

[5] Li, Yan-Ru and Chen, Y. G., "Managing Technology: The Technology Valuation Approach," PICMET 2006 Proceedings, Istanbul, Turkey, 9-13 July 2006.

[6] Rafeiner, O., "IP Assets for Growth: Policy and Practical Issues for Identification and Management," Asia Pacific Regional Forum on the Role of Intellectual Property Offices for Economic and Technological Development, WIPO/IPO/MNL/ 02/3(b), Manila, 3-5 December 2002.

[7] Razgaitis, R., Valuation and Pricing of TechnologyBased Intellectual Property, John Wiley \& Sons, 2003.

[8] Reilly, Robert F. and Garland, Palmela J., "The Valuation of Data Processing Intangible Assets," Valuation of Intangible Assets in Global Operations, F. J. Contractor, ed., Westport, Connecticut: Quorum Books, 2001, pp.205-232.

[9] Reitzig, Markus, "What Determines Patent Value?: Insights from the Semiconductor Industry," Research Policy 32, 2003, pp.13-26.

[10] United Nations Industrial Development Organization, Technology Payments Evaluation: Summary Results of a Pilot Exercise, Caracas (October 17-20), Vienna: UNIDO, 1983.

[11] Van Triest, S. and Vis, W., "Valuing patents on costreducing technology: A case study," International Journal of Production Economics, 105, 2007, pp.282-292. 


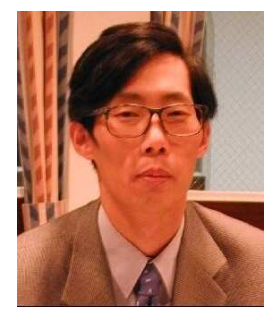

\section{Hyun-Woo Park}

He received the B.S., M.S, and Ph.D. in International Business (1991) from Hong-Ik University, and Ph.D. in Science and Technology Studies (2007) in Korea University. He worked with San Francisco State University (1996-1997) and University of California, Santa Cruz (2008-2009). He is now a technology economist at Korea Institute of Science and Technology Information (KISTI). His main research interests include innovation management, technology commercialization, scientometrics, and technology valuation.

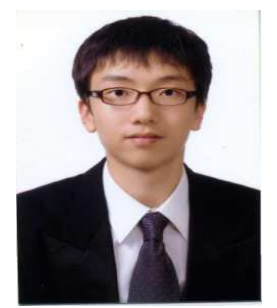

\section{Woo-Taek Shin}

He was born in Seoul. After growing up in Korea, he has studied in the United States since 2007. He is a current student at Shattuck-St. Mary's School in Minnesota, USA. He is a staff of school newspaper and yearbook publications, member of honors program and math team of his school, and columnist of a local newspaper in Minnesota. 